\title{
INNOVATIVE HYBRID TECHNIQUE FOR BILE DUCT EXPLORATION IN THE TREATMENT OF CHOLEDOCHOLITHIASIS
}

\author{
Daniel Navarini ${ }^{1,2,3}$, Henrique Waltrick de Albuquerque ${ }^{1}$, \\ Antônio Benincá Albuquerque ${ }^{3}$, André Luca Boeira Rovani ${ }^{3}$, \\ Deise Dessanti ${ }^{1}$, Diego Reffatti ${ }^{1,2}$, Carlos Augusto Scussel Madalosso ${ }^{1,2}$
}

Clin Biomed Res. 2019;39(4):316-321

1 Departamento de Cirurgia, Hospital São Vicente de Paulo (HSVP). Passo Fundo, RS, Brasil.

2 Departamento de Cirurgia, Clínica Gastrobese. Passo Fundo, RS, Brasil.

3 Faculdade de Medicina, Universidade de Passo Fundo (UPF). Passo Fundo, RS, Brasil.

Corresponding author: Daniel Navarini danielnavarini@hotmail.com Faculdade de Medicina, Universidade de Passo Fundo (UPF)

Rua Teixeira Soares, 817. 99010-080, Passo Fundo, RS, Brazil.

\section{ABSTRACT}

Introduction: Common bile stone disease (CBDS) is frequent and has potentially severe complications, such as acute biliary pancreatitis and cholangitis. Unnecessary and unplanned procedures should be avoided, so before choosing the best treatment of common bile duct lithiasis it is essential to have a proper diagnose. CBDS is currently treated by therapeutic endoscopic retrograde cholangiopancreatography (ERCP) or laparoscopic bile duct exploration (LCBDE).

Results: The aim of this article is to present an innovative hybrid technique for common bile duct exploration, as an option for cases where the laparoscopic approach is not resolutive, avoiding the need for conversion to open approach technique.

Conclusions: The hybrid technique has the same benefits as open and laparoscopic techniques, but without increasing material costs and with good resolution in complex cases of common bile duct stones.

Keywords: Choledocholithiasis; laparoscopic common bile duct exploration; LCBDE; open common bile duct exploration

Common bile duct stone (CBDS) is an extremely common ailment ${ }^{1}$. Bile duct lithiasis can occur by primary or secondary calculi. The primary or autochthone (native) calculi are usually related to chronic bile stasis, due to different factors - biliary stenosis, chronic papillitis, recurrent cholangitis, Oddi's sphincter dysfunction, or pancreatic cholangiopathy. Patients who have been submitted to cholecystectomy and are diagnosed with common bile duct lithiasis after 2 years of surgery are also considered as having primary calculi. Common bile duct stone may occur in 3\%-14\% of patients who have already been submitted to cholecystectomy. Secondary choledocholithiasis accounts for $95 \%$ of cases. It occurs when the stones in the gallbladder migrate to the biliary tree, which is the case in approximately $10 \%-15 \%$ of the people diagnosed with colelitiasis ${ }^{2,3}$.

Clinical presentations requiring investigation for CBDS include epigastric or right upper quadrant pain, especially if associated with jaundice and/or fever. A minority of patients do not present with classical symptoms ${ }^{4}$, because acute pancreatitis or cholangitis may occur due to this disease, so CBDS should also be considered and treated.

On account of several advances in endoscopic techniques, most cases of CBDSs can be solved by endoscopic treatment under endoscopic retrograde cholangiopancreatography (ERCP). Nevertheless, if the endoscope cannot be advanced into the ampulla of Vater, such as with duodenal obstruction due to malignant tumor or surgical anatomy, endoscopic treatment under ERCP may be difficult. Recently, endoscopic ultrasound (EUS)-guided and balloon enteroscopy techniques have been developed. If none of these techniques 
can be used, laparoscopic bile duct exploration (LCBDE) appears to be a safe and reliable method of treating choledocholithiasis, with similar rates of complications and success. The open technique shows better resolution rates, but it is more invasive ${ }^{5,6}$.

The aim of this paper is to show the benefits of the association of laparoscopic and open approach of bile duct exploration by using the hybrid technique.

\section{DIAGNOSIS}

To avoid unnecessary and unplanned procedures, an adequate diagnosis is essential before choosing the best treatment of common bile duct lithiasis. The diagnosis of choledocholithiasis is made before surgery, but also during surgery, always trying to use less invasive techniques first ${ }^{7}$.

The diagnostic method to be chosen is based on a risk stratification for choledocholithiasis - common bile duct dilation on the abdominal ultrasound, biochemical parameters (elevation of transaminases, canalicular enzymes, bilirubin), previous pancreatitis, cholangitis, presence of microcalculi during surgery with evidence of common bile duct dilation, jaundice history, clay-colored stools, and dark urine ${ }^{2,3}$. Moreover, the diagnosis can be done preoperative, intraoperative, or postoperative ${ }^{8}$.

\section{TREATMENT OPTIONS}

When choledocholithiasis is confirmed or strongly suspected preoperatively, ERCP with or without sphincterotomy can be performed, with posterior laparoscopic cholecystectomy (LC). If stones are found during a LC - through an intraoperative cholangiogram -, there are three treatment options: LCBDE, open common bile exploration (preferred in open cholecystectomies), or completion of the cholecystectomy with postoperative ERCP. In cases where choledocholithiasis is diagnosed postoperatively, the best option is ERCP with or without sphincterotomy, although more than one third of the post LC calculi are expelled spontaneously within 6 weeks of operation 8,9 .

Approximately $10 \%-15 \%$ of bile duct stones cannot be treated using conventional stone-removal techniques, and may require other techniques to perform stone-removal, depending on patient factors, such as surgical anatomy and prior surgeries, and stone factors, such as number and size ${ }^{6}$.

The therapeutic decision is based on the available materials and the qualified surgeon. The two choices of intervention are of great importance in the treatment of choledocholithiasis: (1) ERCP before or after surgery, with sphincterotomy and, (2) LCBDE and cholecystectomy. Several randomized studies showed similar effectiveness between both forms of treatment. Kharbutli et al. demonstrated that treating common bile duct lithiasis in one stage (surgical exploration) is associated with less morbidity and mortality $(7 \%$ and $0.19 \%)$ than the 2-stage treatment (ERCP + cholecystectomy) $(13.5 \% \text { and } 0.5 \%)^{3,10-12}$. Furthermore, the single-stage management is associated with lower costs, shorter hospital stays, and higher rates of technical success ${ }^{13,14}$. A recent meta-analysis from Pan et al. confirmed the superiority of $L C B D E+L C$ over preoperative endoscopic sphincterotomy + LC, in perioperative safety and short- and long-term postoperative efficacy ${ }^{15}$.

In some institutions, after therapeutic failure with ERCP, surgery and common bile duct exploration are the choice of treatment, because $50 \%-60 \%$ of patients will have to be submitted to some kind of procedure ${ }^{16}$. Laparoscopic exploration is recommended as the first option in case of ERCP failure. The open approach remains as a final option when other modalities have failed ${ }^{3}$.

The open common bile duct exploration technique is a safe and effective treatment option for choledocholithiasis. Moreover, the laparoscopic advances allowed LCBDE to be performed safely. A prospective and randomized study showed that the surgical time in open and laparoscopic approaches was similar, but the morbidity rate and length of hospitalization were lower in the laparoscopic group. Also, the laparoscopic approach can be performed without increasing the risk of biliary complications and providing quicker recovery and less postoperative pain ${ }^{12,13,17,18}$.

LCBDE can be performed using a transcystic approach or a transcholedochal approach, through choledochotomy. Transcholedochal LCBDE offers greater efficacy for stone clearance, but is associated with higher complication rates compared to transcystic exploration. The number, location, and size of the CBD stones as well as the anatomy of the cystic duct influence the decision of the feasible approach. Transcystic removal is best used on small distal stones. Choledochotomy can be used for large or proximal stones, and should only be considered if the common bile duct is at least $7 \mathrm{~mm}$ in diameter. Lithotripsy is also an option to remove large stones ${ }^{13}$.

\section{TECHNIQUE PERFORMED}

The aim of this article is to describe a hybrid technique for common bile duct exploration, mixing the benefits of a less invasive technique - laparoscopy - and using materials that are used in the open approach, increasing the effectiveness in more complex cases. There is no description of this method in the literature. The complications observed 
in this technique do not differ from those observed in the usual laparoscopic exploration.

First of all, the technique begins as any other videocholecystectomy, performing a pneumoperitoneum, using Veress or Hasson's technique. Subsequently, a $10 \mathrm{~mm}-12 \mathrm{~mm}$ portal is inserted in the supraumbilical region, where the camera is inserted (Figure 1).

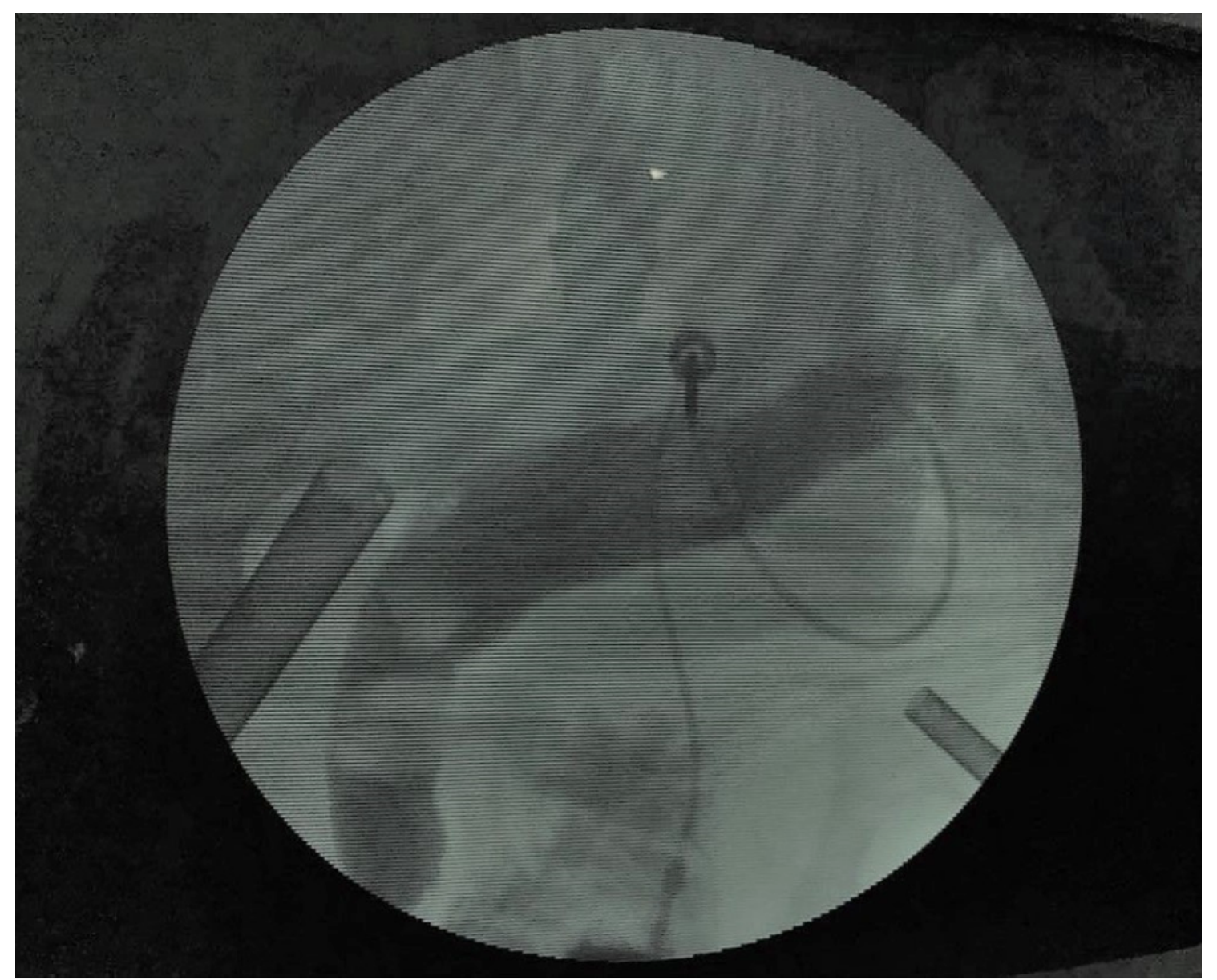

Figure 1: Intraoperative cholangiogram showing multiple calculi.

The patient is positioned in a reverse Trendelenburg and rotated to the left, so the surgeon can have a better surgical view. The surgical procedure goes on as a regular videocholecystectomy, followed by the introduction of the $10 \mathrm{~mm}-12 \mathrm{~mm}$ trocar with an incision below the xiphoid appendix. The other two $5 \mathrm{~mm}$ trocars are inserted in the right hypochondrium and right flank (anterior axillary line), between the costal margin and the superior anterior iliac spine, the first one being used to move the gallbladder and the second for traction.

After the trocars are inserted, the gallbladder is pulled in a cephalic position, by holding its fundus and directing it to the patient's right shoulder. This maneuver allows a better exposure of the infundibulum.

The left hand graspers are used to perform lateral traction at the infundibulum and away from the liver, making adequate tension on the cystic duct. The dissection of the cystic duct and cystic artery is made, in order to obtain a critical view of safety, for an adequate and safe division of these structures.

After the cystic artery is sectioned, the cystic duct is catheterized and cholangiography is performed. The first option is transcystic exploration, but in cases of unviability, a choledochotomy is required. Common bile duct is exposed and incised longitudinally, avoiding the medial and lateral portions of it, so there is no damage to its vascularization. The laparoscopic common bile duct exploration is performed with proper instrumentation - basket, choledoschopy and Fogarty. This technique is effective in most cases.

The hybrid technique is useful in cases where there are more difficulties in extracting the distal stones, with larger diameter, and those impacted, unable to be extracted by the laparoscopic technique, also avoiding conversion to open approach.

The previous incision uses a $5 \mathrm{~mm}$ trocar in the right upper quadrant (right subcostal). The trocar 
is removed and a Randall (used in open common bile duct exploration approach) is placed, with minimum air leakage from the pneumoperitoneum. The Randall with the best curvature is chosen (Figure 2), considering the physical structure of the patient and the anatomic position of the common bile duct. The forceps should be inserted, in a way where the opening and closing are not impaired, usually the limit is the point where it is articulated (Figure 3). Bakes dilators can also be used.

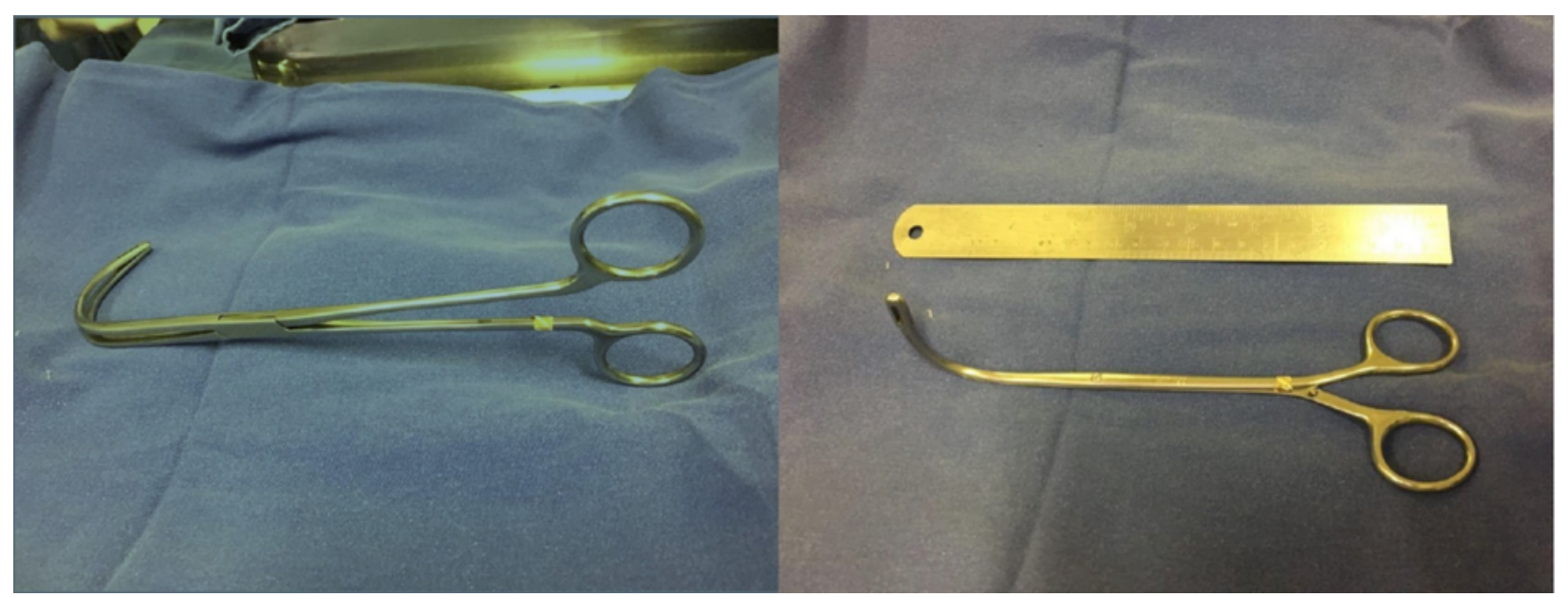

Figure 2: Randall forceps.

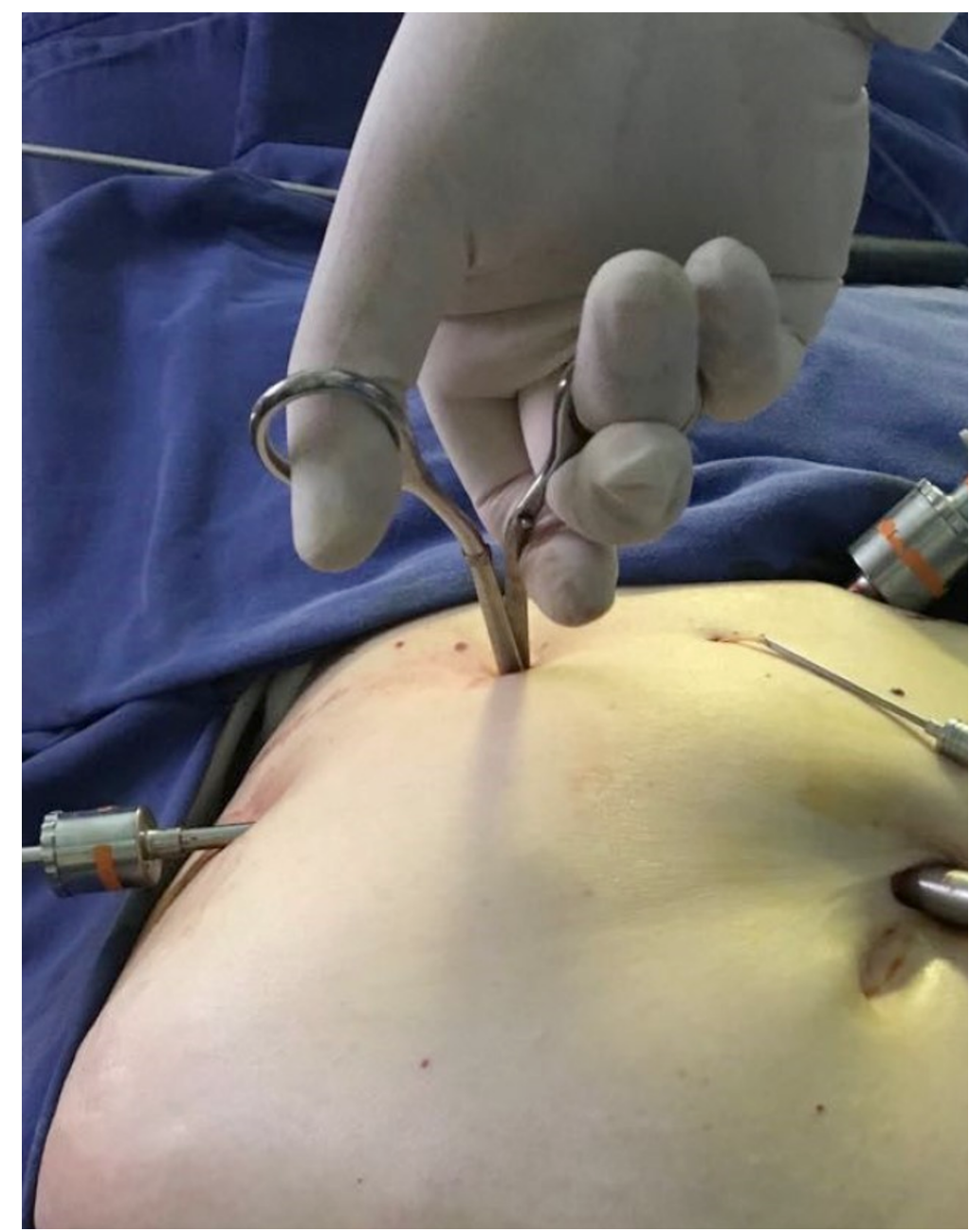

Figure 3: Randall forceps in the right subcostal region. 
The Randall is introduced using the choledochotomy previously performed, conducting the common bile duct exploration with direct visualization by videolaparoscopy. The impacted duct stones are extracted with the help of the Randall forceps (Figure 4).

After the stones are taken out, the Randall forceps is removed and the trocar is put back on. The common bile duct is sutured and the cholangiography is performed. After confirmation of the absence of any stones in the common bile duct, the suture is completed. A Blake drain is placed next to the hepatic hilum, to control any possible leaks that may occur in the suture.

Finally, the abdominal cavity is revised, the trocars are removed with a direct visualization, and the surgery is finished.

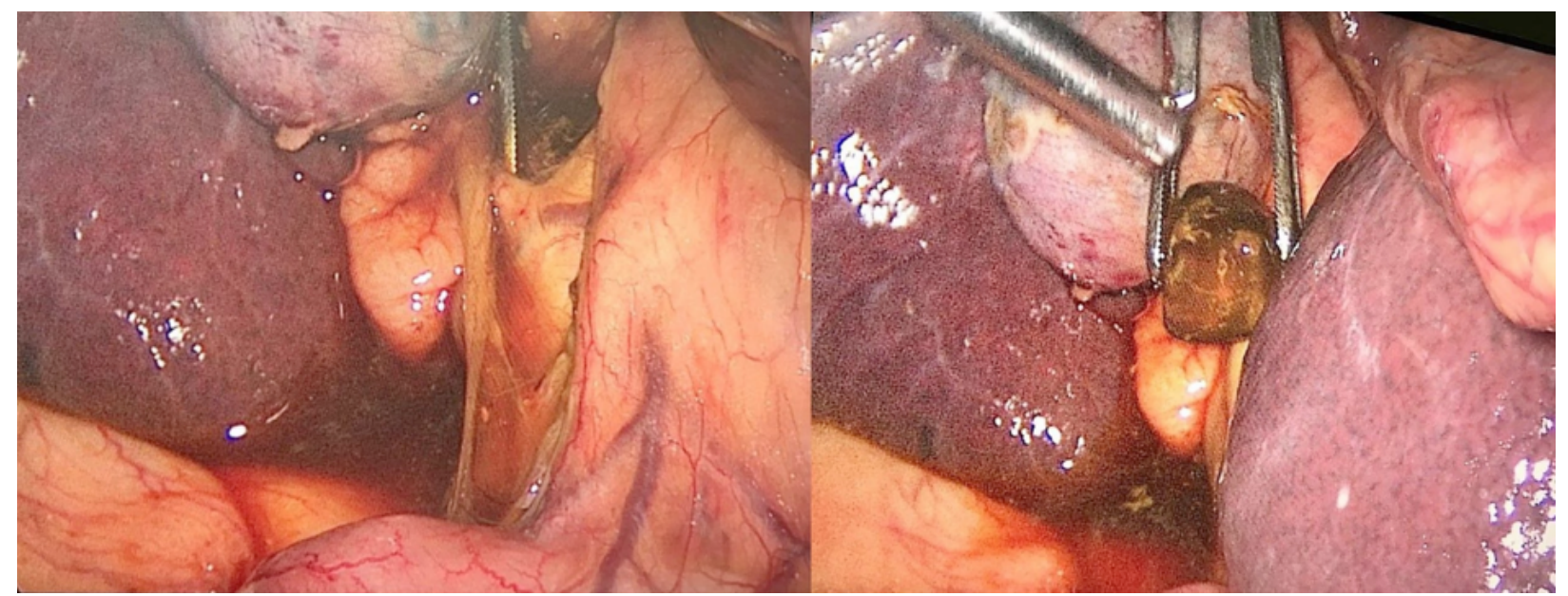

Figure 4: Randall forceps introduced in the common bile duct through choledochotomy (left) and removing calculus of the distal part of the common bile duct (right).

\section{CONCLUSION}

The hybrid technique for common bile duct exploration is an option in cases where the laparoscopic approach is not resolutive, avoiding the need for conversion to the open approach technique. This technique has the advantages of both open and laparoscopic techniques without increasing material costs and with good resolution in complex cases of common bile duct stones.

\section{Conflict of Interests}

The authors declare that there is no conflict of interest regarding the publication of this paper

\section{REFERENCES}

1. Freitas ML, Bell RL, Duffy AJ. Choledocholithiasis: evolving standards for diagnosis and management. World J Gastroenterol. 2006;12(20):3162-7. http://dx.doi. org/10.3748/wjg.v12.i20.3162. PMid:16718834.

2. Rohde L, Osvaldt AB. Rotinas em cirurgia digestiva. $3^{\mathrm{a}}$ ed. Porto Alegre: Artmed; 2018.

3. Shojaiefard A, Esmaeilzadeh M, Ghafouri A, Mehrabi A. Various techniques for the surgical treatment of common bile duct stones: a meta review. Gastroenterol Res Pract. 2009;2009:840208. https:// doi.org/10.1155/2009/840208. PMid: 19672460.

4. Williams E, Beckingham I, El Sayed G, Gurusamy K, Sturgess R, Webster G, et al. Updated guideline on the management of common bile duct stones (CBDS). Gut. 2017;66(5):765-82. https://doi. org/10.1136/gutjnl-2016-312317. PMid:28122906.

5. Bencini L, Tommasi C, Manetti R, Farsi M. Modern approach to cholecysto-choledocholithiasis. World J Gastrointest Endosc. 2014;6(2):32-40. https://doi. org/10.4253/wjge.v6.i2.32. PMid:24567790.

6. Ogura T, Higuchi K. A review of treatment options for bile duct stones. Expert Rev Gastroenterol Hepatol. 2016;10(11):1271-8. https://doi.org /10.1080/17474124.2016.1212658. PMid:27410721.

7. Costi R, Gnocchi A, Di Mario F, Sarli L. Diagnosis and management of choledocholithiasis in the golden age of imaging, endoscopy and laparoscopy. World J Gastroenterol. 2014;20(37):13382-401. https:// doi.org/10.3748/wjg.v20.i37.13382. PMid:25309071.

8. Verbesey JE, Birkett DH. Common bile duct exploration for choledocholithiasis. Surg Clin North Am. 2008;88:1315-28. https://doi. org/10.1016/j.suc.2008.08.002. PMid:18992597.

9. Collins $C$, Maguire D, Ireland A, Fitzgerald E, O'Sullivan GC. A prospective study of common bile duct calculi in patients undergoing laparoscopic cholecystectomy: natural history of choledocholithiasis revisited. Ann Surg. 2004;239(1):28-33. https://doi.org/10.1097/01. sla.0000103069.00170.9c. PMid:14685097. 
10. Poulose BK, Speroff T, Holzman MD. Optimizing choledocholithiasis management: a cost-effectiveness analysis. Arch Surg. 2007;142(1):43-8. https://doi.org/10.1001/ archsurg.142.1.43. PMid:17224499.

11. Wandling MW, Hungness ES, Pavey ES, Stulberg JJ, Schwab B, Yang $A D$, et al. Nationwide assessment of trends in choledocholithiasis management in the United States from 1998 to 2013. JAMA Surg. 2016;151(12):1125-30. https://doi. org/10.1001/jamasurg.2016.2059. PMid:27556900.

12. Way LW, Admirand WH, Dunphy JE. Management of choledocholithiasis. Ann Surg. 1972;176(3):347-59. https://doi.org/10.1097/00000658197209000-00011. PMid:5073221.

13. Zerey M, Haggerty S, Richardson W, Santos B, Fanelli R, Brunt LM, et al. Laparoscopic common bile duct exploration. Surg Endosc.
2018;32(6):2603-12. https://doi. org/10.1007/s00464-017-5991-1. PMid:29273878.

14. Singh AN, Kilambi R. Single-stage laparoscopic common bile duct exploration and cholecystectomy versus two-stage endoscopic stone extraction followed by laparoscopic cholecystectomy for patients with gallbladder stones with common bile duct stones: systematic review and meta-analysis of randomized trials with trial sequential analysis. Surg Endosc. 2018;32(9):3763-76. https:// doi.org/10.1007/s00464-018-6170-8. PMid:29603004.

15. Pan L, Chen M, Ji L, Zheng L, Yan $\mathrm{P}$, Fang $\mathrm{J}$, et al. The safety and efficacy of laparoscopic common bile duct exploration combined with cholecystectomy for the management of cholecysto-choledocholithiasis: an up-to-date meta-analysis. Ann Surg. 2018;268(2):247-53. https://doi. org/10.1097/SLA.0000000000002731. PMid:29533266.
16. Paik KY, Kim EK. Laparoscopic common bile duct exploration after unsuccessful endoscopic stone removal. J Laparoendosc Adv Surg Tech. 2013;23(2):137-40. https:// doi.org/10.1089/lap.2012.0331. PMid:23327344.

17. Feng $Q$, Huang $Y$, Wang $K$, Yuan $\mathrm{R}$, Xiong $\mathrm{X}, \mathrm{Wu} \mathrm{L}$. Laparoscopic transcystic common bile duct exploration: advantages over laparoscopic choledochotomy. PLoS One. 2016;11(9):e0162885. https://doi. org/10.1371/journal.pone.0162885. PMid:27668730.

18. Frazee RC, Roberts J, Symmonds R, Hendricks JC, Snyder S, Smith $\mathrm{R}$, et al. Combined laparoscopic and endoscopic management of cholelithiasis and choledocholithiasis. Am J Surg. 1993;166(6):702-5. https://doi.org/10.1016/s00029610(05)80683-x. PMid:8273853. 